\title{
"BUNANJE": XX CENTURY ABUSE OF ATROPA BELLADONNA HALUCINOGENIC BERRIES IN CONTINENTAL CROATIA
}

\author{
Homage to \\ dr. Miljenko Jakupčević, \\ Zvonimir Lovrenčević and \\ prof. dr. Nenad Bohaček \\ Zdravko Lacković \\ University of Zagreb, School of Medicine, Departments of Pharmacology, Zagreb, Croatia \\ received: 25.1.2017; \\ revised: 3.5.2017; \\ accepted: 7.7.2017
}

\begin{abstract}
SUMMARY
Background: Atropa belladonna (Engl. deadly nightshade, Cro. velebilje, bunika) is a plant containing pharmacologically active, potentially toxic alkaloids: atropine, hyocyamine and scopolamine. The risk of poisoning in children is important because of possible confusion of black/dark blue belladonna fruit berries with other edible berries. There are many reports in literature of accidental intoxication but no report on traditional intentional usage to achieve hallucinogenic effects.

Subjects and methods: Here we report purposeful ingestion of Atropa belladonna berries for hallucinatory effects among adolescents in Bjelovar region in north part of Croatia. This has been happening among children/adolescents while they were grazing animals. We visited a dozen villages in the region and spoke to the oldest mostly to the elderly residents.

Results: The existence of such abuse of Atropa belladonna berries in the first part of XX century was confirmed by eight narrators from five distinct places in the region. Interestingly this type of behavior had a specific name "bunanje", unknown in Croatian language, but clearly associated with local plant name bun or bunika. According to informants consumers of berries would develop delirium or hallucinations associated behavior, incoherent and meaningless speech. However nobody remembers any severe case of poisoning. At the regional hospital in Bjelovar in the Pediatric department, there is no record of poisoning with Atropa belladonna. To our knowledge this is the first report of intentional consumption of belladonna berries to achieve the hallucinogenic effect.

Conclusions: The fact that the custom was observed in five distinct spots and it had its specific name "bunanje" suggest that those are not isolated random events but the type of practices; seasonal abuse of hallucinogenic berries of Atropa belladonna, among rural adolescents in the first part of XX century.
\end{abstract}

Key words: Atropa belladonna - substance abuse - hallucinogen - ethnopharmacology

$* * * * *$

\section{INTRODUCTION}

Atropa belladonna (Engl. deadly nightshade, Cro. velebilje, bun, bunika) is a part of Solanaceae family of plants. Plant usually grow as a subshrub, up to 1.5-2 meters tall with large, $18 \mathrm{~cm}$ long leaves, with some similarity to tobacco. Flowers are purple with a bell like shape. Fruits are berries, of the size of cherries or minitomato $(1.5 \mathrm{~cm})$, with many seeds, with dark purple juice, and a sweet pleasant taste.

Berries contain pharmacologically active alkaloids: atropine, hyocyamine and scopolamine, which in high dose might be very toxic. The name belladonna (It. beautiful women) is associated with its renaissances usage in eye-drops by women to dilate the pupils of the eyes to make them appear seductive (Anon 2017b). On the other hand word atropa, originate from old Greek goodness of destiny, and in Roman time the plant was used as poison. According to some estimation Belladonna is one of the most toxic plants found in the Eastern Hemisphere. The risk of poisoning in children is important because of possible confusion of black/dark blue belladonna fruit berries with other edible berries. There are many reports in literature of accidental intoxication with the plant among adults and children (see Discussion). Here we report purposeful ingestion of Atropa belladonna berries, during first part of $\mathrm{XX}$ century, for hallucinatory effects among rural adolescents in Bilogora region of Croatia.

\section{SUBJECTS AND METHODS}

During the year 1970 we visited 15 villages around Bjelovar and discuss in each with several people, usually older, who know the customs and conditions in the village. We used indirect test procedure:

- First we showed respondents photographs of Atropa belladonna, wondering whether something knowledge of the plant.

- If respondent did not recognize the photograph - we told common, folk names under which belladonna plant is known

- We asked interviewees if they know the meaning of "bunanje" 
- If interviewee did not recall the name „bunanje“ we asked would ask him if he knows of the existence of plant whose berries can make person mad.

- If we see that the subject knows something about it, and are reluctant to talk about it we have used the conventional methods of indirect interviews.

After each interview the notice was made by $\mathrm{Z}$. Lovrenčević or author of present article.

\section{RESULTS}

In total we found 8 people with 5 different addresses in Bjelovar and villages around (Figure 1) it who were able to identify/recoil the custom of usage of frit of Atropa belladonna to deliberately produce hallucinogenic effect (The list of informs is on the table 1). Beside that dozen people in different villages were familiar with appearance of the plant and most of them knew that it is toxic. We heard one interesting story of women who accidently was poisoned and was performing "crazy dancing" in the village after that. This happened about 40 years ago. Surprisingly the story outlived the victim. Another story was that some people used to put Atropa belladonna in vine to become "more crazy" but apparently it was just a gossip without identification of the place or individual.

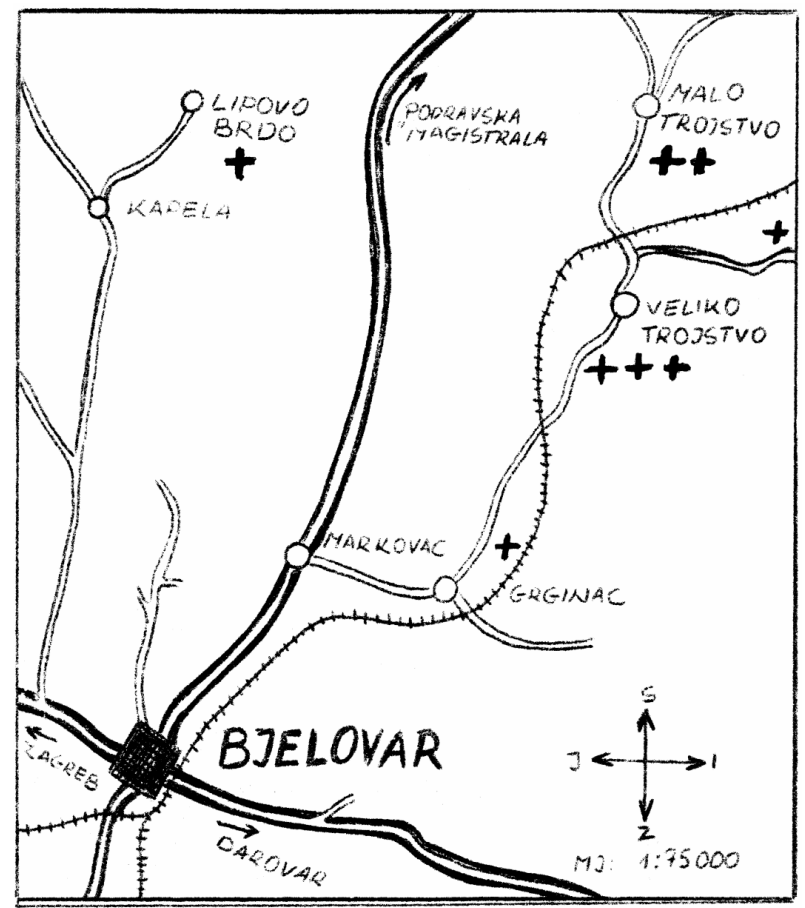

Figure 1. Locations of the spots around Bjelovar where, according to our informers, "bunanje" was taking place (handmade map by author in the year 1970)

\section{Reconstruction of "bunanje" looks as follows:}

Boys in the age of 12 to 13 (Mađarić M and T), shepherds, at the beginning of autumn taking care of cattle grazing play the game they called bunanje ( $\mathrm{Z}$.
Lovrenčević, M. Brajdić, V. Vuk) consisting of consuming ,like tomato, only small like cherry, blue -black, berries of "bunanje trave".

From that "man is like a drunk", "sees everything", "different illusions", "fairies dancing" "beasts that does not exist". Therefore, the one who had eaten the berries "sits on the site" or "runs around" or "dances like crazy" or "scratch with the nails". Beside that the person has open eyes and dry mouth (R. Madjarić). The game would end with participants describing what they experienced in the imaginary world of their hallucinations.

Assuming that there might be some serious poisoning we visited Pediatric ward of Bjelovar General hospital but there was is no record of anticholinergic plant poisoning.

Table 1. Informers who testify intentional usage of Atropa belladonna berries to achieve hallucinogenic effects

\begin{tabular}{ll} 
The informants & $\begin{array}{l}\text { Address at the time } \\
\text { of interview (1970) }\end{array}$ \\
\hline Mladen Brajdić & Bjelovar, Rade Končara 2 \\
Tomo Grbačić & Bulinac \\
Mato Mađarić & Malo Trojstvo \\
Rudolf Mađarić & Malo Trojstvo \\
Vlado Vuk & Bjelovar, I.G. Kovačića 16 \\
Božo Wagner & Bjelovar, Bakarićevo šetalište 30 \\
Jozina Zlatec & Gornje Plavnice, Plavnički \\
& Vinogradi \\
Zvonimir Lovrenčević & Bjelovar, Lenjinova 3 \\
\hline
\end{tabular}

\section{DISCUSSION}

In this paper we describe the deliberate seasonal ingestion of hallucinogenic berries of Atropa among adolescents in north, continental Croatia, near the town of Bjelovar. In the words of eight persons from Bjelovar and several different villages close to Bjelovar, the plant was used in the first half the XX century and they identify four distinct locations (Figure 1) where it was occurring. According to relatively precise locations one is tempting to assume that our informers themselves participated in such event but no one was ready to confess anything like that.

Firs report goes back to 1936 (Wagner) and last one to 1956 (Lovrenčević). Thus such seasonal hallucinogenic berries abuse existed for minimally 20 years. Did "bunanje" exist before that we had no evidence. We have no information if such dangerous "game" existed in other part of Croatia or neighboring countries.

The word bunanje we did not found in available printed or on-line Croatian dictionaries. Instead the similar word buncanje is common meaning: „ravings, delirium, incoherent and nonsensical speech" ... associated with ... "the poisoning with ,bunika", mushrooms etc" (Anon 2017). Thus the main underlying problem was the etymological question: what is meaning of the word "bunanje" and which herb is really 
called „bunika“ in this region of Croatia. There are two possibilities (Anon 2017):

In most of Croatian dictionaries and other sources word „bunika“ is associated with the plant Hyosciamus niger, but sometimes also with Atropa belladonna which is most commonly named velebilje (Anon 2017b, c).

In conclusion ethimologically „bunika“ and bunanje could be associated with Atropa belladonna and Hyosciamus niger. Since both plants contain atropa alkaloids that could produce hallucination description of consumed berries might be a solution of this puzzle:

Atropa belladonna. The common English names for this species include belladonna, deadly nightshade, divale, dwale, banewort, devil's berries, naughty man's cherries, death cherries, beautiful death, great morel, and dwayberry (Grieve 1971, Anon 2017). Croatian common names include: velebilje (most common), bunika, luda trava, vučja trešnja (Anon b, c). Berries of Atropa belladonna are of the size of cherries (1.5 centimeters in diameter, has a dark purple juice, many seeds, juicy sour-sweet delicious taste. The berries are full of a dark, inky juice.

Hyosciamus niger L. Whole plant including leaves, flowers, and fruits are hairy, secreting a resinous substance that causes the fresh leaves to feel unpleasantly clammy and sticky. Whole plant has unpleasant, nauseous odor. The fruit is an oval capsule containing numerous small brownish seeds. Seems unlikely that anybody would enjoy chowing such stinking capsules (Grieve 2017).

In conclusion belladonna sweet cherry like berries cannot be confused by fruit of Hyosciamus niger: an ovate hairy capsule full of brownish seeds with unpleasant odor.

In a fact one of our informer (T. Grabačić) described „,bunanje“ berries: hr.:,,kak paradajz, samo ke črešnja malih plavih, više crnih, bobica“... Eng.: like tomato, only small like cherry, blue, more black, berries". Thus there is little doubt that "bunanje", intentional consumption of hallucinogenic berries is abuse of fruits of Atropa belladonna. The reason of overlapping common names for Atropa belladonna and Hyosciamus niger remains unknown.

In medical literature there are many descriptions of Atropa belladonna poisoning. In Public Medline (PubMed) (accessed April 15, 2015) we found 105 publications. Most of those are case reports of accidental poisoning (Berdai et al. 2012, Bogan et al. 2009) for example due to mistake for blueberries (Mateo Montoya 2009).

According to case analysis from the Swiss Toxicology Information Center in the period 1966-1994 there were 42 cases of belladonna poisoning. Most common symptoms were anticholinergic syndrome (42 cases), acute psychosis (33 caes), convulsions ( 2 cases), coma (2 cases) (Jaspersen-Schib 1996). Caksen et al. in Turkey analyzed 39 children poisoned by belladonna. The most common were anticholinergic syndrome were meaningless speech, tachycardia, mydriasis, and flushing. In PubMed we found 2 cases of fatal poisoning in young children (Gibbons 1954, Laffargue 2010), and only one description of purposeful ingestion of belladonna for hallucinatory effects (Gabel 1968) In 1968 JAMA. Cummings et al. (1968) reported seven patients, between the ages of 15 and 19, treated in Mayo Clinic due to acute belladonna intoxication. It was not intoxication with the plant but with stramonium and belladonna mixture (drug Asthmador ${ }^{\circledR}$ ) used to achieve hallucinogenic effects.

In contrast to over 100 publications on Atropa belladonna poisoning in Pub Med we found only 27 publications on Hyosciamus niger poisoning (15. 04.). In a fact several of them describe poisoning with Datura stramonium (mostly seeds) (Osváth et al. 2000), or are reviews without description of specific case(s). Alizadeh (2014) wrote a more extensive review on Hyosciamus niger poisoning: traditional medicine, accidents or intentional usage are mentioned.

\section{CONCLUSION}

Here we report purposeful ingestion of Atropa belladonna berries for hallucinatory effects among adolescents in Bjelovar region in north part of Croatia. The fact that the custom was observed in 5 separate villages, that it was confirmed by 8 informers, and that 4 distinct locations of such "game" were identifies, and that it had specific name "bunanje" suggest that those are not isolated random events but the type of practices, seasonal abuse of Atropa belladonna berries, among rural adolescents in the first part of XX century.

\section{Acknowledgements:}

In 1970 author of this report and his best friend Miljenko Jakupčević, as students of medicine, learned in Bjelovar, Croatia, from local ethnologists Zvonimir Lovrenčević for custom called "bunanje". Together with him they visited 15 places in Bjelovar region. This discovery was reported at the XII Professional Congress of Students of Medicine and Dentistry of Yugoslavia in Sarajevo on 21-24 April 1971. Notes were made by $Z$. Lovrenčević and author of the article. Preparation of the abstract and presentation for congress was done by M. Jakupčević and author under supervision of Professor N. Bohaček. In May of the same year under recommendation of $\mathrm{N}$. Bohaček this report was awarded by Rector of the University of Zagreb Ivan Supek. Meanwhile, Miljenko Jakupčević, Zvonimir Lovrenčević and Nenad Bohaček passed away and documentation remained misplaced and forgotten until the chief editor of Psychiatria Danubina Miro Jakovljevic on several occasions asked this observation to be written. This paper is author return to the past; reconstruction of 46 years old notices with an overview of recent literature.

Conflict of interest: None to declare. 


\section{References}

1. Alizadeh A, Moshiri M, Alizadeh J, Balali-Mood M: Black henbane and its toxicity - a descriptive review. Avicenna $J$ Phytomed 2014; 4:297-311.

2. Anon a: Buncanje. Proleksis enciklopedija online; Leksikografski zavod Miroslav Krleža. http://proleksis. lzmk.hr/59336/ (accessed 15.04.2017)

3. Anon b: Atropa Belladonna, and Atropos: Wikipedia. https://en.wikipedia.org/wiki/Atropa_belladonna and https://en.wikipedia.org/wiki/Atropos

4. Anon C: Velebilje (Atropa belladonna) https://www.themajka.com/viewtopic.php? $t=71$ (accessed 15. 04.2017)

5. Berdai MA, Labib S, Chetouani K, Harandou M: Tropa belladonna intoxication: a case report. Pan Afr Med J 2012; 11:72.

6. Bogan R, Zimmermann T, Zilker T, Eyer $F$, Thiermann $H$ : Plasma level of atropine after accidental ingestion of Atropa belladonna. Clin Toxicol (Phila) 2009; 47:602-4.

7. Caksen H, Odabass D, Akbayram S, Cesur Y, Arslan S, Uner A, Oner AF: Deadly nightshade (Atropa belladonna) intoxication: an analysis of 49 children. Hum Exp Toxicol 2003; 22:665-8.

8. Cummins BM, Obetz SW, Wilson MR: "Belladonna poisoning as a facet of pschyodelia". JAMA 1968; 204:1011.

9. Gabel MC: Purposeful ingestion of belladonna for hallucinatory effects. J Pediatr 1968; 72:864-6.

10. Gibbons WD: Deadly nightshade poisoning. Med J Aust 1954; 41:254-5.
11. Grieve M: Henbane. In: Modern Herbal http://www.botanical.com/botanical/mgmh/h/henban23.ht ml\#des (accessed March 15, 2017)

12. Laffargue F1, Oudot C, Constanty A, Bedu A, KettererMartinon $S$ : [Deadly nightshade (Atropa belladonna) intoxication in a 2-year-old child]. Arch Pediatr 2011; 18:186-8.

13. Grieve M, Leyel CF: Modern Herbal. Courier Dover Publications. 1971. p. 584. (Cit prema Wikipedia: Atropa belladonna https://en.wikipedia.org/wiki/Atropa_belladonna) (accessed 15. 04.2017)

14. Jaspersen-Schib $R$, Theus L, Guirguis-Oeschger $M$, Gossweiler B, Meier-Abt PJ: [Serious plant poisonings in Switzerland 1966-1994. Case analysis from the Swiss Toxicology Information Center]. Schweiz Med Wochenschr 1996; 126:1085-98. [Article in German]

15. Mateo Montoya A, Mavrakanas N, Schutz JS: Acute anticholinergic syndrome from Atropa belladonna mistaken for blueberries. Eur J Ophthalmol 2009; 19:170-2.

16. Moshiri M, Alizadeh J, Balali-Mood M: Black henbane and its toxicity - a descriptive review. Avicenna $J$ Phytomed 2014; 4:297-311.

17. Osváth P, Nagy A, Fekete S, Tényi T, Trixler M, Radnai I: A case of datura stramonium poisoning - general problems of differential diagnosis. Orv Hetil 2000; 141:133-6. [Article in Hungarian]

18. Trabattoni G, Visintini D, Terzano GM, Lechi A: Accidental poisoning with deadly nightshade berries: a case report. Hum Toxicol 1984; 3:513-6.

Correspondence:

Professor Zdravko Lacković, MD, PhD

University of Zagreb, School of Medicine, Departments of Pharmacology

Šalata 11, 10000 Zagreb, Croatia

E-mail: zdravko.lackovic@mef.hr 